\title{
Identificando a relação entre alavancagem financeira e investimento nas empresas brasileiras não financeiras de capital aberto
}

\section{Identifying the relationship between financial leverage and investment in non financial Brazilian public companies}

\begin{abstract}
Andrei Aparecido de Albuquerque
Doutor em Administração de Organizações; Mestre em Controladoria e Contabilidade pela USP/FEARP; MBA em Controladoria e Finanças pela FUNDACE/USP; Bacharel em Ciências Contábeis pela USP/FEA- RP; Docente do Departamento de Engenharia de Produção da Universidade Federal de São Carlos andrei@dep.ufscar.br
\end{abstract}

\author{
Alberto Borges Matias \\ Doutor, Mestre e Bacharel em Administração pela \\ Universidade de São Paulo; Professor Titular da \\ USP; Docente do Departamento de Administração \\ da FEA- RP/USP \\ matias@usp.br
}

Contextus

ISSNe 2178-9258

Organização: Comitê Científico Interinstitucional Editor Científico: Marcelle Colares Oliveira Avaliação: Double Blind Review pelo SEER/OJS Revisão: Gramatical, normativa e de formatação Recebimento: 30/01/2013 Aprovação: 27/12/2013

\section{RESUMO}

O objetivo deste trabalho foi examinar se a alavancagem financeira afeta as decisões de investimento das empresas brasileiras não financeiras de capital aberto. $O$ estudo foi desenvolvido com testes para o período de 2001 a 2011, utilizando-se do método de regressão linear múltipla com dados em painel usando efeitos fixos e efeitos aleatórios. Pelos resultados encontrados, pode-se afirmar que existe uma forte relação negativa entre alavancagem financeira e investimento nas empresas brasileiras não financeiras de capital aberto. Esse relacionamento negativo é ainda mais intenso nas empresas com baixas oportunidades de crescimento.

Palavras-chave: Alavancagem financeira. Investimento. Estrutura de capital. Capital de terceiros. Oportunidades de crescimento.

\begin{abstract}
The objective of this work was to examine if financial leverage affects investment decisions of Brazilian non financial public companies. This study was carried out with tests from 2001 to 2011 by using the method of multiple linear regression with panel data using fixed and random effects. The results show that there is a strong negative relation between financial leverage and investment in the Brazilian non financial public companies. This negative relationship is more intense in companies with low growth opportunities.
\end{abstract}

Keywords: Financial leverage. Investment. Capital structure. Debt capital. Growth opportunities. 


\section{INTRODUÇÃO}

Segundo Lang, Ofek e Stulz (1996), um assunto recorrente na teoria de finanças tem sido a forma como uma empresa é financiada, ou seja, sua estrutura de capital, e se essa forma afeta o valor da firma, sua rentabilidade e sua política de investimentos. A participação de capital de terceiros na estrutura de capital das empresas é pertinente em função do efeito da alavancagem financeira que, como afirma Assaf Neto (2009, p. 121), é “[...] o efeito de tomar, numa ponta, recursos de terceiros a determinado custo, aplicando-os na outra ponta (nos ativos) a outra taxa de retorno". Assim, ao se utilizar de dívidas, uma empresa tem a possibilidade de aumentar a remuneração dos seus proprietários e, consequentemente, seu valor, por captar recursos a uma taxa e aplicá-los em outra possivelmente maior, embora com essa decisão passe a elevar seu risco, justamente pelo fato de assim passar a ter o compromisso com os credores que realizaram o empréstimo.

As discussões da existência ou não de uma estrutura ótima de capital iniciaram-se com as proposições de Modigliani e Miller (1958), pois, por meio de um cenário hipotético, esses autores propuseram a irrelevância da estrutura de capital da empresa para a determinação do seu valor.
Desde então, uma série de pesquisas tem sido realizada na expectativa de testar ou comprovar a existência dessa estrutura ótima de capital ou sua irrelevância, entretanto, como afirma Myers (1984), pouco ainda se sabe ou pode ser confirmado acerca da escolha dessa estrutura de capital das empresas.

Mesmo Modigliani e Miller (1963), nesse artigo posterior ao original, reviram sua posição e realizaram uma correção na proposição inicial argumentando que, em um mundo com impostos, a alavancagem financeira passa a ser relevante, uma vez que o uso do capital de terceiros traz um benefício fiscal para a empresa em função de o seu custo ser dedutível da base tributária, fato que não ocorre com o capital próprio.

Myers (2001) pondera razões que tornam o uso de dívidas relevante para a atuação das empresas, a saber: os impostos, as diferenças nas informações e os custos de agência. E esses elementos permeiam as principais teorias sobre a estrutura de capital.

A estrutura de capital passou a ser considerada um aspecto relevante seja do ponto de vista da determinação do valor das empresas, para sua operação, seja em termos teóricos, tendo a compreensão da composição das fontes de financiamento das empresas se tornado um assunto de interesse para muitas pesquisas. No campo 
teórico, podem-se citar, entre vários estudos, os clássicos: Modigliani e Miller (1958, 1963); Miller (1977); Myers (1977; 1984); Harris e Raviv (1991) e Myers (2001). Muitos outros trabalhos empíricos foram e ainda são desenvolvidos acerca desse tema, entre eles tem-se mais recentes: Bastos e Nakamura (2009); Frank e Goyal (2009); Gungoraydinoglu e Öztekin (2011); Kayo e Kimura (2011); Devos et al. (2012) e Yang (2013).

Em contraste, autores como Bates (2005) e Cleary, Povel e Raith (2007) argumentaram sobre a significância dos fluxos gerados internamente pelas empresas para definição de seus investimentos, inclusive considerando os fluxos de caixa como o principal fator determinante dessa decisão. Entretanto, Ahn, Denis e Denis (2006) afirmaram que a literatura de estrutura de capital tem argumentado que alavancagem financeira e investimento são fortemente relacionados. Nessa vertente há a posição de Myers (1977), que afirma que a alta alavancagem financeira pode fazer com que a empresa abandone projetos com valor presente líquido (VPL) positivo em função das pressões financeiras geradas pelas dívidas existentes. Por outro lado, Jensen (1986) e Stulz (1990) comentam que, embora exista uma relação negativa entre alavancagem financeira e investimento, o uso de dívidas pode ser benéfico aos acionistas porque as dívidas limitam o poder discricionário dos gerentes sobre o uso dos fluxos de caixa das empresas. A alavancagem financeira só é possível com o uso de capital de terceiros na composição de financiamento da empresa, isto é, na sua estrutura de capital, identificando-se, assim, a estreita relação entre esses conceitos.

Com base nessas considerações sobre a pertinência e a atenção dada ao assunto estrutura de capital, em uma perspectiva sobre a utilidade do endividamento, considera-se que as empresas podem captar mais recursos de terceiros visualizando a possibilidade de aproveitar oportunidades de investimento. Dessa forma, estariam se valendo dos benefícios da alavancagem financeira, seja para abarcar aquelas oportunidades que não poderiam devido à indisponibilidade de recursos internos e/ou próprios seja para obter benefício de utilizar recursos com custo mais baixo.

Autores como Lang, Ofek e Stulz (1996) e Aivazian, Ge e Qiu (2005) buscaram entender a relação entre alavancagem financeira e investimento das empresas. A compreensão dessa questão tem considerável relevância, pois perceber uma relação positiva entre tais variáveis significaria notar que as empresas com maiores níveis de investimento também são aquelas que mais se utilizam de 
capitais de terceiros, beneficiando-se assim dos efeitos da alavancagem financeira. Em contraposição, uma relação negativa evidenciaria que empresas com maiores proporções de dívida em sua estrutura de capital tenderiam a ter menores níveis de investimento. Como os estudos anteriores foram realizados em economias desenvolvidas, entende-se como relevante aplicar um estudo nesse tema no Brasil, por se tratar de um país em desenvolvimento, portanto, com características distintas daqueles países já investigados, o que tornaria possível verificar o comportamento dessas variáveis em uma economia distinta. Assim, o objetivo traçado para esta pesquisa foi examinar se a alavancagem financeira afeta as decisões de investimento das empresas brasileiras não financeiras de capital aberto. A próxima seção apresenta a contribuição da literatura que ampara este trabalho.

\section{REFERENCIAL TEÓRICO}

Este tópico foca os principais conceitos teóricos e os trabalhos empíricos que fundamentam a execução desta pesquisa.

\subsection{Estrutura de Capital}

Segundo Myers (2001, p. 81), o estudo da estrutura de capital tenta explicar a combinação de fontes de recursos de títulos de propriedade e empréstimos para financiar seus investimentos. Dessa forma, entende-se a estrutura de capital como a proporção de recursos próprios (ações/títulos de propriedade) e recursos de terceiros (dívidas) utilizado para financiar as atividades da empresa, bem como seus investimentos. Como a alavancagem financeira consiste na capacidade de utilizar recursos de terceiros buscando sua aplicação em oportunidades de investimento que gerem taxas de remuneração maior que o custo desses recursos, é possível perceber uma associação entre os conceitos de estrutura de capital, alavancagem financeira e investimento.

De acordo com Perobelli e Famá (2002), existem basicamente duas grandes correntes teóricas acerca da estrutura de capital: a tradicionalista, também chamada de teoria convencional, representada principalmente por Durand (1952), e a de Modigliani e Miller (1958).

Segundo Famá, Barros e Silveira (2001), a corrente tradicionalista prega a existência de uma estrutura ótima de capital, ou seja, uma combinação de utilização de capitais próprios e de 
terceiros que permite atingir um nível mínimo do custo de capital, o qual seria o ponto ótimo. Com um custo mínimo de capital é possível admitir um valor máximo da empresa; assim, essa corrente acredita que a estrutura de capital influencia o valor da empresa, pois, conforme Durand (1952), o custo de capital de terceiros permanece estável até determinado nível, o que faz com que sua utilização seja atrativa para a empresa. Depois desse ponto, o custo de captação (juros exigidos) se elevaria em função do maior risco a que os emprestadores ficariam expostos. Portanto, o custo de capital deixaria esse "nível ótimo" depois de um determinado volume de dívidas.

A vertente alternativa proposta por Modigliani e Miller (1958) apresenta a ideia de que, considerando determinadas condições, a estrutura de capital não tem influência sobre o valor da empresa, já que, segundo esses autores, o custo de capital permaneceria inalterado independentemente da composição de financiamentos utilizada pela organização. Dessa forma, não existiria um nível ótimo de endividamento que garantisse um custo mínimo de capital, permanecendo o valor da empresa inalterado independentemente da forma como ela é financiada. Assim, o valor da empresa não é uma função da maneira como ela é financiada, mas sim dos seus fluxos de caixa gerados e do risco associado às suas atividades.

Desde o clássico trabalho de Modigliani e Miller (1958), a pesquisa acerca do tema estrutura de capital passa a ter um forte impulso, tornando-se um dos temas mais pesquisados na literatura sobre finanças. Embora mais de 50 anos tenham se passado desde esse trabalho, muito pouco ainda se tem como cientificamente comprovado ou sem questionamentos na literatura acadêmica. Myers (1984, p. 575), respondendo à pergunta "Como as empresas escolhem suas estruturas de capital?", afirma: "Nós não sabemos". E apesar de transcorrido um tempo considerável, pesquisas mais recentes, como a de Valle (2008), continuam concordando com essa afirmação, relatando pequenos avanços desde tal pesquisa, mantendo a relevância dos estudos relativos a esse tema, mesmo com o enorme número de trabalhos dedicados a ele.

Há muitas pesquisas voltadas a identificar a proporção de capital próprio e de terceiros utilizada nas empresas. A despeito disso, como afirma Myers (2001), não há uma teoria universal sobre a escolha entre dívidas e ações, muito menos uma razão para que isso ocorra. Nesse sentido, Miller (1991), embora tenha recebido o prêmio Nobel por estudo nessa linha de 
pesquisa, alega que deve ser considerado apenas o primeiro e não o último a realizar descobertas acerca da proporção de endividamento. Assim, os estudos continuam a ser realizados nessa perspectiva na busca de mais evidências sobre esse assunto tão pertinente na realidade e na atuação das empresas.

$\mathrm{Na}$ concepção de que não existe uma corrente única que defina a escolha da estrutura de capital das empresas, Myers (2001) agrupou trabalhos sobre esse tema em três vertentes teóricas: a static tradeoff, a pecking order e a free cash flow. Conforme Myers (1984), a static tradeoff é a teoria que afirma que a empresa estabelece uma proporção alvo de dívida e capital próprio, a qual busca atingir. Esse mesmo autor diz que a teoria de pecking order argumenta que há uma hierarquia de preferência de fontes de recursos, sendo inicialmente os recursos internos, posteriormente a emissão de dívidas e em terceiro lugar a emissão de ações. Já a teoria do free cash flow de Jensen (1986) enfatiza o uso das dívidas como elemento disciplinador dos gerentes, fazendo-os utilizar de forma mais coerente os fluxos de caixa da empresa, impedindo desperdício de recursos financeiros. Myers (2001) finalizou sua argumentação sobre a teoria do free cash flow informando que ela não é de fato uma teoria para a predição de como os gestores escolhem ou decidem a sua estrutura de capital, mas sim uma teoria que se relaciona a consequências de altas proporções de dívidas.

Essas são as principais correntes teóricas sobre a estrutura de capital, e o uso de capital de terceiros nessa composição é o que possibilita o efeito da alavancagem financeira que, como já exposto, trata-se do efeito de captar recursos por uma taxa e aplicar em investimentos com base em outra taxa que produz rentabilidade superior. Apesar do estabelecimento dessas teorias, ainda persiste o desenvolvimento de várias pesquisas em diversas frentes relacionadas à estrutura de capital. Trabalhos recentes como, por exemplo, o de Frank e Goyal (2009), o de Kayo e Kimura (2011) e o de Gungoraydinoglu e Öztekin (2011), entre tantos outros, buscam identificar os fatores determinantes da estrutura de capital. Ao identificar tais fatores, uma empresa poderia escolher entre utilizar mais ou menos alavancagem financeira.

Outras pesquisas, como a de Fama e French (2002) e a de Jong, Verbeek e Verwijmeren (2011), testam evidências empíricas das diferentes teorias de estrutura de capital, especialmente a static tradeoff e a pecking order. Se fosse identificada a preponderância de uma teoria sobre a outra, os gestores teriam condições de focar seus esforços na melhor compreensão dos aspectos dessa teoria 
mais influente e assim seria possível conseguir os melhores resultados da alavancagem financeira na execução de seus investimentos.

Kirch e Terra (2012) focalizaram em outra vertente dessa discussão ao buscar os determinantes da maturidade da dívida, ou seja, além da opção pelo capital de terceiros na estrutura de capital, cujo prazo de vencimento também poderia ser explorado. Esses autores identificaram que a qualidade das instituições em sua respectiva nação é relevante na definição da estrutura de capital e no prazo da dívida. Assim, a alavancagem financeira poderia inclusive ser avaliada em uma conjuntura de dívidas de curto e de longo prazo.

Kahle e Stulz (2013) identificaram comportamentos diferentes nas políticas de financiamento (e também de investimento) para empresas que se utilizam de endividamento bancário, ou seja, alavancagem financeira, e empresas não alavancadas em um período de crise financeira. Seus resultados demonstraram que, no período de crise, as empresas com maior nível de alavancagem financeira tiveram uma redução de investimentos proporcionalmente menor que as empresas não alavancadas. Tais resultados se alinham com a concepção dos motivos que levam as empresas a financiar os investimentos com dívidas, tratada no próximo item.
2.2 Discussão sobre Uso de Dívida para Financiar Investimento

Segundo Ross, Westerfield e Jordan (2008), o processo de alocação de capital, mais comumente denominado de investimento, é uma das principais decisões financeiras a que estão sujeitos os administradores financeiros das empresas.

As diferentes razões de investimento, como ampliação, substituição ou renovação de ativos imobilizados, entre outras, fazem com que as empresas busquem fontes de recursos que possibilitem a sua realização. Autores como Childs, David e Ott (2005) argumentam sobre diferentes comportamentos em relação à opção de investimento dependendo da razão, por exemplo, no caso da expansão ou da substituição. Gitman (2010) afirma que as organizações tratam de forma separada o processo de investimento e as decisões de financiamento. Apesar disso, elas estão intrinsecamente ligadas. Se a organização opta por aplicar recursos seja de qualquer forma ou objetivo necessitará definir qual (ou quais) será (ou serão) a(s) fonte(s) desses recursos. Nesse contexto, as duas principais teorias de estrutura de capital apresentam pertinência: a static tradeoff, que indica o uso de dívidas até certo ponto em função dos benefícios tributários trazidos por elas em contraste com os 
potenciais custos de dificuldades financeiras, e a pecking order, que defende uma hierarquia de fontes de financiamento na sequência de lucros retidos, dívidas e emissão de ações.

Há divergências entre as argumentações sobre o uso de recursos de terceiros no financiamento de investimentos. Cantor (1990), por exemplo, relatou que aumentos na alavancagem financeira das empresas estão relacionados com elevações na volatilidade dos investimentos. $\mathrm{O}$ autor afirmou que seus resultados indicaram que a alta variabilidade das empresas com elevados níveis de alavancagem financeira aparenta ser consequência da capacidade de resposta das demandas do investimento às flutuações dos fundos gerados internamente, ou seja, o uso de capitais de terceiros seria uma alternativa em face da ausência de recursos gerados internamente, mas que causaria maior volatilidade na empresa. Por outro lado, Whited (1992) informou que seus resultados sugeriram que dificuldades na obtenção de dívidas têm um impacto nos investimentos. Os autores ainda argumentaram que qualquer tentativa de entendimento da decisão de investimentos deveria considerar o acesso da empresa às dívidas disponíveis no mercado. Assim, percebe-se a relevância do uso de dívidas na perspectiva de realização de investimentos das empresas.
De acordo com Stulz (1990, p. 23), "A debt issue that requires management to pay out funds when cash flows accrue reduces the overinvestment cost but exacerbates the underinvestment cost". Com esse entendimento, percebe-se que a dívida exerce um papel positivo e um negativo na decisão de investimentos. Nesse sentido, Jackson, Keune e Salzsieder (2013) argumentam que seus resultados suportam os argumentos da teoria que demonstra os gestores relutantes no uso das dívidas para o financiamento dos seus ativos, decorrendo tal comportamento da existência de dois erros possíveis: a) com receio de usar dívidas, os gestores poderiam deixar de optar ou aplicar em investimentos que poderiam aumentar o valor da empresa; b) com disponibilidade de caixa proporcionada pela dívidas, os gestores poderiam aceitar investimentos que destroem o valor da empresa.

$\mathrm{Na}$ verdade, conforme Hackbarth e Mauer (2012), as decisões de investimento e financiamento interagem em modelos dinâmicos, fazendo com que as empresas tenham de analisar múltiplas questões relacionadas às dívidas e aos detentores de ações para efetuar suas escolhas, inclusive de timing, de investimento. Esse comportamento de interação mencionado por esses autores se assemelha ao alinhamento de políticas de financiamento e investimento argumentado por Kahle e 
Stulz (2013), os quais identificaram comportamento de queda de investimentos em um período de crise, proporcionalmente superior para empresas não alavancadas em relação às empresas com uso mais intenso de dívidas. Os resultados de Kahle e Stulz (2013) podem inclusive ser interpretados como argumento na defesa do uso de dívidas para financiar investimentos.

Com esse cenário de duas posições sobre o uso de dívidas para financiar investimentos tem-se o aspecto que propulsiona os testes deste trabalho, assim o próximo item relata alguns trabalhos empíricos que estudam o relacionamento entre as variáveis de interesse desta pesquisa.

\subsection{Estudos sobre a Relação da} Alavancagem Financeira e o Investimento

Lang, Ofek e Stulz (1996) relataram uma forte correlação negativa entre suas medidas de crescimento e a alavancagem financeira. Também demonstraram que o $Q$ de Tobin tem correlação negativa com a alavancagem financeira e positiva com as medidas de crescimento.

Os autores aplicaram modelos de regressão linear múltipla para verificar a relação entre as variáveis. Afirmam ter realizado regressões para cada ano. Com os resultados de suas regressões, indicam uma forte relação negativa entre a alavancagem financeira e suas variáveis de crescimento. Os autores reaplicaram seus testes ajustando as variáveis pelos efeitos da indústria (setor) e os resultados obtidos também demonstram forte relação negativa da alavancagem financeira e do crescimento.

$$
\text { Aivazian, Ge e Qiu (2005) }
$$

examinaram a relação entre investimento e alavancagem financeira nas empresas canadenses de capital aberto. Afirmam que os estudos prévios focaram o mercado dos Estados Unidos da América, ao utilizarem dados do Canadá, como esses países semelhantes em termos institucionais e de relações seu trabalho permite a comparação dos resultados entre duas amostras similares embora independentes. Utilizaram dados do Compustat Canadian 1999 Annual File, arquivo que inclui dados financeiros, estatísticos e de mercado das 1.035 maiores empresas industriais canadenses existentes até o fim do ano de 1999. Os dados cobrem o período de 1982 a 1999, e após as devidas checagens e exclusões ficaram com um painel desbalanceado de 6.231 observações de 863 empresas.

Os autores ainda utilizaram uma regressão linear múltipla para estimar a relação entre investimento e alavancagem financeira, valendo-se de um modelo com dados em painel. Em seus resultados, 
relatam que a alavancagem financeira tem um efeito negativo sobre o investimento no nível de significância de 1\%. Essa relação negativa permanece independente das impactos positivos e significantes no investimento.

Conforme Ahn, Denis e Denis (2006), há muitos anos o relacionamento entre alavancagem financeira e oportunidades de investimento é um tema de interesse nas pesquisas em finanças. Nessa perspectiva, os autores examinaram a associação entre a alavancagem financeira e o investimento em empresas diversificadas. Aplicaram modelos de regressão cross section, onde a variável dependente foi o investimento ajustado pela indústria (industry-adjusted). A variável independente foi o excesso de alavancagem financeira, definido como a diferença entre proporção de dívida total da empresa pelo valor contábil dos ativos totais e alavancagem financeira inserida (imputed leverage) da empresa. Utilizaram as variáveis de controle Q de Tobin e fluxos de caixa operacional ajustados pela indústria. De forma geral, suas variáveis são semelhantes às utilizadas por Lang, Ofek e Stulz (1996). Incluíram ainda variáveis dummy para os anos e efeitos fixos das empresas no seu modelo de regressão, para controlar os efeitos de séries temporais e efeitos fixos, além de variáveis utilizadas e dos modelos estatísticos empregados. Afirmam também que o $\mathrm{Q}$ de Tobin, o fluxo de caixa operacional e as vendas têm variáveis de controle para segmentos core.

Ahn, Denis e Denis (2006) afirmam que seus resultados são consistentes com os reportados por Lang, Ofek e Stulz (1996), indicando que o investimento ajustado pelo segmento de indústria é negativamente relacionado com o excesso de alavancagem financeira em nível de empresa. Apontam também que essa relação negativa é significativamente mais forte para segmentos de altos $\mathrm{Q}$ do que para baixos Q e significativamente menos negativa para segmentos core do que para segmentos não core. Os autores ainda relatam que os padrões de investimento e de alavancagem financeira observados em seu trabalho são significativamente distintos para empresas diversificadas e para aquelas focadas (que atuam em apenas um segmento). Ahn, Denis e Denis (2006) concluem que seus resultados têm impacto na literatura sobre políticas de investimento em empresas diversificadas.

Firth, Lin e Wong

(2008) argumentaram que em uma economia onde ocorre predominância de bancos estatais (state-owned banks) o relacionamento entre a alavancagem financeira e o investimento é afetado 
por esse aspecto, pois essas instituições financeiras são controladas por políticos que as utilizam para maximizar seus próprios objetivos políticos e pessoas. Assim o objetivo dos autores foi investigar as relações entre investimento, alavancagem financeira, crescimento $\mathrm{e}$ desempenho para empresas de capital aberto da China.

Firth, Ling e Wong (2008) relatam, como primeiro resultado, uma relação negativa entre alavancagem financeira $\mathrm{e}$ investimento, consistente com estudos anteriores e demonstrativa da existência da relevância da dívida mesmo em uma economia com predominância de bancos estatais. Em segundo lugar, relatam que a relação negativa entre alavancagem financeira e investimento é mais fraca para empresas com baixas oportunidades de crescimento e fraco desempenho operacional do que para aquelas com altas oportunidades de crescimento e bom desempenho operacional. No terceiro resultado, os autores apontam que a relação negativa entre alavancagem financeira $\mathrm{e}$ investimento é mais fraca nas empresas com um alto nível de participação estatal em sua propriedade do que naquelas com níveis menores. Concluem que todos os seus resultados são consistentes com a hipótese de que bancos estatais impõem menores barreiras no empréstimo de recursos para empresas que são de propriedade do estado e que têm baixo desempenho ou poucas oportunidades de crescimento, fato que pode enfraquecer o efeito disciplinador da dívida e propiciar o sobreinvestimento nessas empresas.

Dang (2011) argumentou que as pesquisas costumam ser conduzidas de forma a analisar separadamente aspectos de investimento e alavancagem financeira. Por isso, considera presente e importante a questão de como as estratégias de financiamento e investimento interagem em um quadro dinâmico no qual as oportunidades de crescimento relacionadas aos investimentos da empresa afetam sua alavancagem financeira e a maturidade das dívidas, as quais, por sua vez, exercem influência sobre suas decisões de investimento. Assim, traçou como objetivo investigar empiricamente, utilizando uma abordagem unificada, as relações interdependentes entre a alavancagem financeira, a estrutura de maturidade da dívida, as oportunidades de crescimento e o investimento. Em seus resultados, Dang (2011) argumenta que empresas com altas oportunidades de crescimento reduzem a alavancagem financeira, dedução consistente com a hipótese de Myers (1977) a respeito da utilização de baixa alavancagem financeira para evitar incentivos ao subinvestimento.

A próxima seção dedica-se aos aspectos metodológicos desta pesquisa. 


\section{METODOLOGIA}

Esta seção tem a finalidade de explorar os aspectos metodológicos utilizados pelo estudo como será visto na sequência.

\subsection{Especificação da Pesquisa}

Este estudo tem por objetivo examinar se a alavancagem financeira afeta as decisões de investimento das empresas brasileiras não financeiras de capital aberto. Portanto, há o interesse de analisar as consequências do uso de capital de terceiros no nível de investimentos das empresas, podendo este trabalho ser classificado como explicativo, pois, conforme Richardson (1999), esse tipo de estudo é aquele que deseja analisar as causas ou consequências de um fenômeno.

Em função do emprego de quantificação neste trabalho tanto na coleta de informações quanto em seu tratamento por meio de técnicas estatísticas, esta pesquisa utilizará o método quantitativo, podendo assim ser classificada como quantitativa (RICHARDSON, 1999).

\subsection{Coleta de Dados}

Para a realização desta pesquisa, foram coletadas informações disponíveis no banco de dados da Economática das empresas de capital aberto brasileiras, no período de 2000 a 2011. Utilizou-se a classificação por setor do próprio banco de dados, de onde foram extraídos dados das demonstrações financeiras das empresas de capital aberto, sendo excluídas as empresas do setor financeiro.

Após essa seleção inicial, foram excluídas as informações das empresas que em algum dos anos apresentaram Patrimônio Líquido negativo, pois essa condição prejudica o perfil de investimento da empresa e afeta as suas condições de captação de recursos por se tratar de uma posição diferente do considerado ideal para uma corporação, em que o valor total de ativos é inferior à soma de todas suas dívidas.

Como será tratado mais adiante, os testes são realizados com variáveis defasadas em um ano. Dessa forma, para as análises, o investimento de um ano é comparado com variáveis do ano anterior, razão por que, apesar de os dados serem coletados a partir do ano 2000, os modelos são efetivamente empregados no período de 2001 a 2011.

\subsection{Modelo Empírico Aplicado}

No intuito de verificar o relacionamento entre a alavancagem financeira e o investimento nas empresas brasileiras não financeiras de capital aberto, será utilizado o modelo de regressão linear múltipla proposto por Aivazian, Ge e Qiu (2005) com amparo 
nas definições de Lang, Ofek e Stulz (1996), com as extensões necessárias para aplicação da técnica de análise com painel de dados.
A expressão do modelo utilizado é a seguinte:

$\mathrm{INV}_{i, t} / \mathrm{I}_{i, t-1}=\beta_{0}+\beta_{1}\left(\mathrm{FC}_{\mathrm{i}, \mathrm{t}} / \mathrm{I}_{\mathrm{i}, \mathrm{t}-1}\right)+\beta_{2} Q_{i, t-1}+\beta_{3} \mathrm{ALAV}_{i, t-1}+\beta_{4}\left(\mathrm{VEND}_{\mathrm{i}, \mathrm{t}-1} / \mathrm{I}_{\mathrm{i}, \mathrm{t}-1}\right)+\lambda_{t}+\mu_{i}+\varepsilon_{i, t}$

Onde:

INVi,t $=$ investimento da empresa i no ano t.

Ii,t-1 = ativos fixos (imobilizado) da empresa i no ano t-1.

FCi,t = fluxo de caixa da empresa i no ano t.

$Q_{i, t-1}=Q$ de Tobin da empresa $i$ no ano $t-1$. $\operatorname{ALAV}_{i, t-1}=$ alavancagem financeira da empresa $i$ no ano $t-1$.

$\operatorname{VEND}_{i, t-1}=$ vendas líquidas da empresa $i$ no ano $t-1$.

$B_{0}=$ constante do modelo.

${ }_{t}=$ conjunto de variáveis dummy de tempo para controle de possíveis diferenças no ambiente macroeconômico de cada ano.

$i=$ efeito individual da empresa $i$.

$i, t=$ termo de erro.

3.4 Modelo para Oportunidades de Crescimento

Trabalhos anteriores, como os de McConnell e Servaes (1995), Lang, Ofek e Stulz (1996), Ahn, Denis e Denis (2006) e
Dang (2011), relataram a importância da consideração das oportunidades de crescimento em trabalhos que relacionam as decisões de financiamento com as de investimento em função das diferenças de percepção no uso do capital de terceiros para empresas com baixas oportunidades de crescimento e aquelas que apresentam altas oportunidades de crescimento. Harris e Raviv (1991) também afirmaram que os estudos disponíveis apontam as oportunidades de crescimento como um dos fatores que incentivam o crescimento da alavancagem financeira.

Para cobrir essa lacuna, Aivazian, Ge e Qiu (2005) inseriram uma variável em seu modelo de estimação que pudesse captar as diferenças relacionadas às oportunidades de crescimento apresentadas pelas empresas de sua amostra. Com procedimento semelhante ao desses autores, nesta pesquisa foi empregada a seguinte equação (2)

$$
\begin{aligned}
\mathrm{INV}_{i, t} \Lambda_{i, t-1}= & \beta_{0}+\beta_{1}\left(\mathrm{FC}_{\mathrm{i}, \mathrm{t}} / \mathrm{I}_{\mathrm{i}, \mathrm{t}-1}\right)+\beta_{2} Q_{i, t-1}+\beta_{3} \mathrm{ALAV}_{i, t-1}+\beta_{4} D_{i, t-1} \times \mathrm{ALAV}_{i, t-1}+ \\
& \beta_{5}\left(\mathrm{VEND}_{\mathrm{i}, \mathrm{t}-1} / \mathrm{I}_{\mathrm{i}, \mathrm{t}-1}\right)+\lambda_{t}+\mu_{i}+\varepsilon_{i, t}
\end{aligned}
$$


, onde todas as variáveis são idênticas ao modelo base, mas agora há a inserção da variável $D_{i, t-1}$, que se trata de uma dummy retratando as oportunidades de crescimento da empresa $i$ no ano $t$ - 1 , sendo igual a 1 quando o $Q$ de Tobin é maior do que 1 e igual a zero em caso contrário. Nesta pesquisa também foram empregados testes com esse segundo modelo, que estima as diferenças de oportunidades de crescimento.

\subsection{Variáveis Utilizadas}

O modelo de regressão linear múltipla, conforme expresso na seção 3.3, foi empregado em uma abordagem de análise com dados em painel neste estudo. Para tanto, uma série de variáveis foram utilizadas na pesquisa, cujas formas de apuração serão a seguir definidas.

\subsubsection{Variável dependente:}

\section{- Investimento (INV) - é o} investimento "líquido" da empresa conforme proposto por Lang, Ofek e Stulz (1996). Neste trabalho, o cálculo dessa medida foi baseado em Assaf Neto (2009), que estabelece o investimento como o saldo da subtração entre o valor dos passivos de funcionamento e o valor total dos ativos.

\subsubsection{Variáveis independentes:}

- Fluxo de Caixa (FC) - é o fluxo de caixa, conforme definido por Aivazian, Ge e Qiu (2005), que é apurado pela soma dos lucros antes dos itens extraordinários e da depreciação. Neste trabalho, seguindo o anterior e respeitando as limitações de dados disponíveis na base, foi apurado pela adição ao lucro líquido da depreciação das empresas em cada exercício social.

- $Q$ de Tobin $(Q)-Q$ de Tobin é o índice que relaciona o valor de mercado da firma com o custo de reposição de seus ativos, apontado por vários trabalhos, como os de McConnell e Servaes (1995), como um indicador de oportunidades de crescimento. Como afirmam Famá e Barros (2000), entre outros autores, a apuração do $Q$ de Tobin na prática é bem difícil, pelo fato de ser complexo o problema de obtenção do valor de reposição dos ativos, o que leva à utilização de aproximações na aplicação desse indicador. Seguindo as definições de Shin e Stulz (2000), essa variável, neste estudo, foi calculada pela soma do valor de mercado das ações multiplicado pelo número de ações ao valor contábil das dívidas (passivo), dividida pelo valor contábil do ativo total. 
- Alavancagem Financeira (ALAV) medida da alavancagem financeira da empresa. Essa variável foi utilizada por Lang, Ofek e Stulz (1996) e Firth, Lin e Wong (2008) como a relação entre a dívida (passivo) total e o ativo total. Já Aivazian, Ge e Qiu (2005) utilizaram duas medidas alternativas, sendo uma de dívidas totais e outra com dívidas de longo prazo divididas pelo ativo total. Neste trabalho, foi utilizada, para indicar a alavancagem financeira, a razão entre o total das dívidas (passivo) e o ativo total.

- Vendas (VEND) - vendas líquidas estabelecidas por Aivazian, Ge e Qiu (2005). Nesta pesquisa, essa medida será representada pelo valor da receita líquida disponibilizada na Demonstração de Resultado de Exercício (DRE) de cada empresa nos respectivos períodos.

\subsection{Procedimentos Estatísticos Aplicados}

Devido ao fato de que o banco de dados estabelecido contém informações de diversas empresas ao longo de vários períodos (anos), foi escolhida a metodologia estatística de dados em painel, a mesma utilizada nesse tema de pesquisa por Aivazian, Ge e Qiu (2005).

Inicialmente, foram aplicados dois modelos básicos de regressão com dados em painel: de efeitos fixos e de efeitos aleatórios. O modelo de efeitos fixos considera que embora os interceptos variem entre os indivíduos (no caso, empresas) eles não variam com o tempo, daí o termo "efeitos fixos", conforme Gujarati e Porter (2011). Esse modelo admite que pode ocorrer a existência de variáveis não observáveis, por consequência, não incluídas no modelo, que são relevantes e podem estar correlacionadas com uma ou mais variáveis independentes inseridas no modelo. O modelo de efeitos aleatórios, por sua vez, assume que todas as formas de distinção das empresas que não foram inseridas no modelo não possuem nenhum tipo de correlação com a variável dependente. Assim, esse modelo reconhece que qualquer variável não inclusa no modelo faz parte do termo de erro.

Num segundo estágio, foi determinado o modelo mais ajustado para as análises. Para identificar qual o modelo que apresenta os estimadores mais adequados a dado modelo, Gujarati e Porter (2011) sugerem a aplicação do teste de Hausman. Esse teste trabalha com a hipótese nula de que os estimadores do modelo de efeitos fixos e aqueles de efeitos aleatórios não diferem substancialmente, isto é, a diferença não é sistemática. Com a rejeição da hipótese nula, conclui-se que o modelo de efeitos aleatórios não é 
adequado, devido ao fato de que os efeitos aleatórios provavelmente estão correlacionados com um ou mais regressores, situação em que o modelo de efeitos fixos é preferível ao modelo de efeitos aleatórios.

Em função da potencial existência de heteroscedasticidade e autocorrelação dos resíduos, o terceiro procedimento de testes foi utilizar o método de Newey-West para parâmetros mais robustos, cujos detalhes podem ser verificados em Newey e West (1987). Os resultados obtidos são apresentados e discutidos na próxima seção.

\section{APRESENTAÇÃO DE RESULTADOS E ANÁLISES}

Esta seção dedica-se à apresentação e discussão dos resultados obtidos com os procedimentos e testes realizados na pesquisa.

\subsection{Aspectos Estatísticos Iniciais}

De posse da base de dados, ou seja, com o painel estabelecido, foram realizadas em um primeiro momento as estatísticas descritivas das variáveis deste estudo. Os números obtidos podem ser observados na Tabela 1.

Tabela 1 - Estatística descritiva das variáveis das 247 empresas no período de 2001 a 2011

\begin{tabular}{|c|c|c|c|c|c|}
\hline $\begin{array}{c}\text { Variáveis } \\
\text { (1525 observações) }\end{array}$ & Média & Desvio- Padrão & Mediana & Mínimo & Máximo \\
\hline Investimento $_{t} /$ Imobilizado $_{t-1}$ & 2,2628 & 1,5612 & 1,8195 & 0,0005 & 9,9596 \\
\hline Fluxo de Caixat/Imobilizado ${ }_{t-1}$ & 0,2141 & 0,3956 & 0,1580 & $-3,3709$ & 5,9084 \\
\hline$Q$ de Tobin $_{\mathrm{t}-1}$ & 1,2468 & 0,7741 & 1,0319 & 0,1168 & 8,8883 \\
\hline Alavancagem Financeira $\mathrm{t}_{\mathrm{t}-1}$ & 0,5717 & 0,1915 & 0,5805 & 0,0008 & 1,5679 \\
\hline Vendas $_{\mathrm{t}-1} /$ Imobilizado $_{\mathrm{t}-1}$ & 2,2709 & 1,9563 & 1,6088 & 0,0000 & 9,9837 \\
\hline
\end{tabular}

Fonte: elaboração própria.

Nota: A alavancagem financeira é obtida pela divisão entre o passivo (dívidas) total e o ativo total.

Pelos resultados encontrados, podese observar, preponderantemente, que a média do nível de investimento $(2,2628)$ em relação ao ativo fixo (imobilizado) das empresas no período é muito semelhante à média das vendas $(2,2709)$ pelo mesmo denominador. Isso indica que ao longo dos períodos as empresas conseguem obter um volume de vendas que se iguala ao montante de investimento médio mantido por elas. Tais resultados, embora possam configurar mera coincidência, também 
podem indicar um alinhamento entre $\mathrm{o}$ volume de vendas realizadas e a execucação de investimentos, isto é, vender mais leva à possibilidade de maiores investimentos, assim como uma retração nas vendas acarreta o contrário. Os números de mínimo e máximo dessas duas variáveis também se apresentaram bastante semelhantes. Em uma comparação com o trabalho de Aivazian, Ge e Qiu (2005), nota-se que a média dos investimentos das empresas brasileiras não financeiras de capital aberto é bem maior, 2,26 contra 0,17 nesse estudo anterior, por outro lado a média de vendas é bastante inferior, 2,27 contra 4,50 .

Percebe-se uma forte oscilação dos números de fluxo de caixa. Embora essa variável tenha apresentado média de 0,2141, os números de mínimo e máximo mostram que as empresas no período chegaram a ter de um fluxo de caixa negativo de $-3,37$ a um elevado fluxo positivo de aproximadamente 5,91.

A alavancagem financeira média das empresas brasileiras foi de 0,5717 , o que indica que mais de $57 \%$ dos ativos das empresas brasileiras selecionadas neste estudo é financiado por capital de terceiros, fato que corrobora o entendimento de relevância desse elemento para a definição de investimentos das corporações.

$\mathrm{Na}$ sequência de análises foram apuradas as correlações das variáveis do estudo. Segundo Triola (2005, p. 381), “[...] existe uma correlação entre duas variáveis quando uma delas está relacionada com a outra de alguma maneira". Já de acordo com Stevenson (2001, p. 341), “[...] a correlação mede a força, ou grau, de relacionamento entre duas variáveis". Assim, essa etapa dos testes permitirá verificar se há relacionamento entre as variáveis e em qual intensidade ela se apresenta. A Tabela 2 apresenta os resultados obtidos. 
Identificando a relação entre alavancagem financeira e investimento nas empresas brasileiras não financeiras de capital aberto

Tabela 2 - Correlações entre as variáveis das 247 empresas no período de 2001 a 2011

\begin{tabular}{|c|c|c|c|c|c|}
\hline $\begin{array}{c}n=1525 \\
\text { observações }\end{array}$ & $\mathrm{INV}_{\mathrm{i}, t} / \mathrm{I}_{\mathrm{i}, \mathrm{t}-1}$ & $\mathrm{FC}_{\mathrm{i}, \mathrm{t}} / \mathrm{I}_{\mathrm{i}, \mathrm{t}-1}$ & $Q_{\mathrm{i}, \mathrm{t}-1}$ & $\operatorname{ALAV}_{\mathrm{i}, \mathrm{t}-1}$ & $\operatorname{VEND}_{\mathrm{i}, \mathrm{t}-1} / \mathrm{I}_{\mathrm{i}, \mathrm{t}-1}$ \\
\hline $\mathrm{INV}_{\mathrm{i}, \mathrm{t}} / \mathrm{I}_{\mathrm{i}, \mathrm{t}-1}$ & 1,0000 & & & & \\
\hline $\mathrm{FC}_{\mathrm{i}, \mathrm{t}} / \mathrm{I}_{\mathrm{i}, \mathrm{t}-1}$ & 0,2928 & 1,0000 & & & \\
\hline$Q_{\mathrm{i}, \mathrm{t}-1}$ & 0,1646 & 0,1532 & 1,0000 & & \\
\hline $\operatorname{ALAV}_{\mathrm{i}, \mathrm{t}-1}$ & $-0,2132$ & $-0,0932$ & 0,0397 & 1,0000 & \\
\hline $\begin{array}{c}\text { VEND }_{\mathrm{i}, \mathrm{t}} \\
{ }_{1} / \mathrm{I}_{\mathrm{i}, \mathrm{t}-1}\end{array}$ & 0,5730 & 0,2848 & 0,2554 & $-0,0143$ & 1,0000 \\
\hline
\end{tabular}

Fonte: elaboração própria.

Notas: as variáveis estão expressas por suas respectivas siglas, sendo investimento (INV); fluxo de caixa (FC); $Q$ de Tobin $(Q)$; alavancagem financeira (ALAV); vendas (VEND) e imobilizado (I). A alavancagem financeira é obtida pela divisão entre o passivo (dívidas) total e o ativo total. Os resultados foram obtidos pela aplicação do software Stata.

$$
\text { Conforme os resultados }
$$
apresentados, pode-se notar a maior correlação existente entre investimento e vendas, que foi de 0,5730 e é consistente com os números médios similares constatados para essas variáveis e já comentados aqui. Percebe-se ainda que vendas foi a variável com maior correlação também com fluxo de caixa $(0,2848)$ e $Q$ de Tobin $(0,2554)$, respectivamente $\mathrm{o}$ terceiro e o quarto maiores índices de correlação encontrados no estudo, esse último denotando que as vendas são um elemento importante para a determinação de oportunidades de crescimento pelo mercado. Chama-se a atenção ao fato de que em todos esses casos o relacionamento é positivo. A variável vendas só apresenta um relacionamento negativo com a variável alavancagem financeira $(-0,0143)$, a qual também é a mais fraca apurada entre as variáveis.

A segunda correlação mais intensa observada foi entre as variáveis fluxo de caixa e investimento, que foi de 0,2928. Esse índice está em acordo com as afirmações de Bates (2005) e Cleary, Povel e Raith (2007) sobre a importância dos fluxos de internos para as decisões de investimentos. Como já mencionado, existe relacionamento positivo entre fluxo de caixa e vendas, com correlação de 0,2848 , o que indica um comportamento do fluxo de caixa acompanhando o que ocorre com as vendas. O fluxo de caixa ainda apresenta uma correlação de 0,1532 com o $Q$ de Tobin, demonstrando que pode ser um elemento importante para elevar as expectativas do mercado em relação à empresa. Da mesma forma que vendas, o 
fluxo de caixa apresenta uma correlação negativa com a alavancagem financeira e, embora ela seja baixa $(-0,0932)$, é consistente com a ideia de que empresas com maior geração de fluxo de caixa tendem a utilizar menos recursos de terceiros, e coerente com a teoria de pecking order de Myers (1984).

O $Q$ de Tobin também apresenta correlação positiva com todas as variáveis, embora a mais elevada seja com vendas $(0,2554)$. A segunda correlação mais alta é com a variável investimento, no montante de 0,1646 , indicando que as oportunidades de crescimento realmente podem ser um elemento importante na determinação dos investimentos das empresas.

A alavancagem financeira, como já descrito, apresenta uma baixa correlação negativa com vendas $(-0,0143)$ e fluxo de caixa (-0,0932). Apresenta ainda uma correlação baixa, embora positiva, com o $Q$ de Tobin, com índice de 0,0397 , o que possibilita inferir que não é um bom indicador para a determinação das oportunidades de crescimento das empresas. A correlação de maior interesse com base no tema desta pesquisa é a existente entre a alavancagem financeira e os investimentos, que, neste estudo, foi de -0,2132, índice consistente com os argumentos Myers (1977) de que essa relação deveria ser negativa em função dos problemas de agência entre acionistas e credores, e também com as indicações de relacionamento nesse perfil dadas por Jensen (1986) e Stulz (1990).

Apresentados esses resultados mais preliminares de estatísticas descritivas e correlações, o próximo subtópico começa a apresentar os resultados dos testes com os modelos de regressão.

\subsection{Testes do Impacto da Alavancagem}

Financeira no Investimento

Após a identificação dos primeiros resultados com os dados desta pesquisa, percebeu-se uma sinalização de que as variáveis empregadas se alinham em termos de vetor dos coeficientes para o que se espera em termos das teorias existentes. Em suma, a variável alavancagem financeira demonstra uma correlação negativa com o investimento e as demais variáveis apresentam correlação positiva com a variável dependente.

$\mathrm{Na}$ sequência, deve-se aplicar testes mais robustos para verificar esse relacionamento, e assim foram aplicados os modelos de regressão para aprofundar o entendimento da dependência da variável investimento em relação às demais variáveis especificadas no modelo, em especial a alavancagem financeira. Segundo Gujarati e Porter (2011), a análise de regressão é indicada para o estudo da dependência de uma variável em relação a uma ou mais variáveis independentes. 
Como exposto no capítulo 3 , o método escolhido foi o de regressão linear múltipla com dados em painel. A Tabela 3 apresenta os resultados obtidos com os testes empregados.

Tabela 3 - Resultados das regressões com modelo de estimação da equação de investimento (empresas $=247$, período de 2001 a 2011)

\begin{tabular}{|c|c|c|c|c|c|c|c|c|c|}
\hline & \multicolumn{3}{|c|}{ Efeitos Fixos (EF) } & \multicolumn{3}{|c|}{ Efeitos Aleatórios (EA) } & \multicolumn{3}{|c|}{ Efeitos Fixos (EF), NW } \\
\hline $\begin{array}{c}\text { Variáveis } \\
\text { Independentes }\end{array}$ & Beta & $\begin{array}{l}\text { Erro- } \\
\text { padrão }\end{array}$ & p-val & Beta & $\begin{array}{c}\text { Erro- } \\
\text { padrão }\end{array}$ & p-val & Beta & $\begin{array}{c}\text { Erro- } \\
\text { padrão }\end{array}$ & p-val \\
\hline $\mathrm{FC}_{\mathrm{i}, \mathrm{t}} / \mathrm{I}_{\mathrm{i}, \mathrm{t}-1}$ & 0,218 & 0,067 & 0,001 & 0,262 & 0,065 & 0,000 & 0,218 & 0,090 & 0,016 \\
\hline$Q_{\mathrm{i}, \mathrm{t}-1}$ & 0,099 & 0,044 & 0,024 & 0,087 & 0,041 & 0,035 & 0,099 & 0,042 & 0,018 \\
\hline $\mathrm{ALAV}_{\mathrm{i}, \mathrm{t}-1}$ & $\begin{array}{c}- \\
0,878\end{array}$ & 0,216 & 0,000 & $\begin{array}{c}- \\
1,141\end{array}$ & 0,196 & 0,000 & $\begin{array}{c}- \\
0,878\end{array}$ & 0,254 & 0,001 \\
\hline $\mathrm{VEND}_{\mathrm{i}, \mathrm{t}-1} / \mathrm{I}_{\mathrm{i}, \mathrm{t}-1}$ & 0,412 & 0,024 & 0,000 & 0,405 & 0,021 & 0,000 & 0,412 & 0,035 & 0,000 \\
\hline Dummy tempo & 0,101 & 0,054 & 0,062 & 0,123 & 0,054 & 0,022 & 0,101 & 0,058 & 0,082 \\
\hline Constante & 1,627 & 0,143 & 0,000 & 1,829 & 0,150 & 0,000 & & & \\
\hline $\mathrm{N}^{\circ}$ Observações & \multicolumn{3}{|c|}{1525} & \multicolumn{2}{|c|}{$\mathrm{N}^{\circ}$ Observações } & 1525 & \multicolumn{2}{|c|}{$\mathrm{N}^{\circ}$ Observações } & 1517 \\
\hline Prob $>F$ & \multicolumn{3}{|c|}{0,0000} & \multicolumn{2}{|c|}{ Prob>chi2 } & 0,0000 & \multicolumn{2}{|c|}{ Prob $>F$} & 0,0000 \\
\hline $\mathrm{R}^{2}$ & \multicolumn{3}{|c|}{0,2414} & \multicolumn{2}{|c|}{$\mathrm{R}^{2}$} & 0,2402 & \multicolumn{2}{|c|}{$\mathrm{R}^{2}$} & 0,2414 \\
\hline \multicolumn{10}{|l|}{ Hausman fixed } \\
\hline \multicolumn{10}{|c|}{$\begin{array}{c}\text { Test: Ho: difference in coefficients not } \\
\text { systematic }\end{array}$} \\
\hline \multicolumn{10}{|c|}{$\operatorname{chi} 2(5)=(b-B)^{\prime}\left[\left(V_{-} b-V \_B\right)^{\wedge}(-1)\right](b-B)=18,31$} \\
\hline $\begin{array}{c}\text { Prob }>\text { chi } 2= \\
0,0026\end{array}$ & & & & & & & & & \\
\hline
\end{tabular}

Fonte: elaboração própria.

Notas: as variáveis estão expressas por suas respectivas siglas, sendo investimento (INV); fluxo de caixa (FC); $Q$ de Tobin $(Q)$; alavancagem financeira (ALAV); vendas (VEND) e imobilizado $(\mathrm{I})$. Beta $=$ coeficientes, $\mathrm{p}$-val. $=$ nível de significância dos coeficientes. Prob $>F$, Prob $>$ chi2 $=$ nível de significância do modelo. $R^{2}=$ coeficiente de explicação do modelo. A alavancagem financeira é obtida pela divisão entre o passivo (dívidas) total e o ativo total. Os resultados foram obtidos pela aplicação do software Stata.

Pela aplicação do teste de Hausman, identifica-se que o modelo de efeitos fixos é o que mais se ajusta ao caso, já que rejeitou a hipótese nula de que a diferença entre os coeficientes no modelo de efeitos fixos e no de efeitos aleatórios não é sistemática. Dessa forma, no estudo analisa-se o modelo de efeitos fixos. Conforme apontado na metodologia, foi utilizado o método de Newey-West para a obtenção de parâmetros robustos.
Pelos resultados obtidos, nota-se que o modelo é válido e tem um poder de explicação da variável dependente de aproximadamente $24 \%$, superior ao reportado por Aivazian, Ge e Qiu (2005) de $8,8 \%$ no modelo de efeitos fixos. As variáveis utilizadas no modelo apresentaram significância ao nível de 5\%, com exceção das variáveis dummy de tempo, que ainda assim se mostraram significativas ao nível de $10 \%$. Nota-se 
ainda que as variáveis alavancagem financeira e vendas foram as de maior significância em termos estatísticos (nível de $1 \%$ ) e também com maior poder de explicação dos coeficientes, $-0,878$ e 0,412 , respectivamente. O fluxo de caixa apresentou poder explicativo de 0,218 e o menor poder explicativo foi o da variável $Q$ de Tobin, de 0,099. Apesar disso, reafirma-se que a variável foi significativa e, portanto, importante na capacidade explicativa da variável dependente exposta no modelo.

Com relação aos sinais dos coeficientes das variáveis, identifica-se que eles também seguiram o comportamento esperado pela teoria, todos com uma relação positiva com a variável dependente, com exceção da alavancagem financeira, que, como previsto, tem uma relação negativa. Esses resultados se assemelham aos encontrados por Lang, Ofek e Stulz (1996), Aivazian, Ge e Qiu (2005) e Firth, Lin e Wong (2008).

A variável alavancagem financeira foi a que apresentou um maior (em módulo) coeficiente de estimação no modelo, sendo de $-0,878$. Tal resultado se assemelha ao ocorrido no estudo de Aivazian, Ge e Qiu (2005), entretanto nesse estudo o coeficiente estimado foi de 0,335 no modelo de efeitos fixos. Tal fato permite entender que, para as empresas brasileiras não financeiras de capital aberto, a alavancagem financeira tem um impacto mais forte na determinação dos investimentos do que para as empresas canadenses, ou seja, para uma economia mais desenvolvida, ao menos no período de estudo. Esse comentário poderia ser estendido também em relação à China pelo resultado do coeficiente nessa variável obtida por Firth, Lin e Wong (2008), que foi de -0,332. Entretanto, como o modelo empregado por esses autores tem variações em relação ao de Aivazian, Ge e Qiu (2005), é preciso ter mais cuidado com as interpretações, portanto se atentará mais a comparações apenas com o trabalho canadense, já que é a base do modelo aqui utilizado. Ressalta-se ainda a consistência dos resultados com os argumentos de autores como Myers (1977), Jensen (1986) e Stulz (1990) sobre a expectativa de que a alavancagem financeira tenha uma relação negativa com o investimento, tendo em vista que as pressões financeiras ocasionadas pelas dívidas podem provocar o abandono de projetos com VPL positivo pelas empresas.

Outra comparação em relação ao estudo de Aivazian, Ge e Qiu (2005) é que o fluxo de caixa apresentou um estimador no montante de 0,021 , se tornando apenas o segundo menos importante do modelo. Neste estudo, essa variável teve um poder explicativo de 0,218 , ou seja, mais de dez vezes maior a sua importância no modelo 
com empresas brasileiras não financeiras de capital aberto. Assim, pode-se afirmar que a variável fluxo de caixa também é mais relevante aqui que na realidade do Canadá na explicação do investimento. $\mathrm{O}$ mesmo também ocorre com a variável vendas; no estudo canadense essa variável apresenta o pior coeficiente de estimação, sendo de 0,010, enquanto na presente pesquisa revela o segundo maior estimador, de 0,412. Em suma, fluxo de caixa e vendas se apresentam como mais significativos determinantes do investimento das organizações no Brasil que no Canadá.

O próximo item tratará da variação no modelo básico em função da busca de uma maior compreensão do papel das oportunidades de crescimento na determinação do investimento.

\subsection{Testes com Oportunidades de Crescimento}

A Tabela 4 mostra os resultados obtidos conforme o modelo especificado no item 3.4. Novamente todas as variações do modelo de regressão aplicadas foram significativas.

O teste de Hausman nessa nova tentativa também apontou o modelo de efeitos fixos como o mais indicado para essa situação. Da mesma forma descrita na seção anterior, optou-se pela utilização do método de Newey-West para a obtenção de parâmetros mais robustos no modelo de estimação.

O coeficiente de explicação $\left(R^{2}\right)$ foi de $24,26 \%$, ou seja, mantém-se no mesmo patamar, embora seja um pouco superior ao encontrado no modelo base, que foi de 24,14\%. Em comparação ao trabalho de Aivazian, Ge e Qiu (2005), novamente o poder de explicação do nosso modelo foi bastante superior, pois no estudo anterior essa equação variante apresentou um poder de explicação de $9 \%$.

Mais uma vez os resultados obtidos pelos estimadores em termos de sinal acompanham o comportamento esperado conforme os argumentos da literatura. $\mathrm{Na}$ gama de variáveis, apenas a alavancagem financeira apresenta um relacionamento negativo com o investimento, e todas as demais demonstram uma relação positiva.

Em comparação com os resultados do modelo base apresentados no subtópico anterior, os estimadores de fluxo de caixa, $Q$ de Tobin, vendas e também da dummy de tempo sofreram leve redução, respectivamente, $-0,004,-0,019,-0,005$ e 0,007. Em contrapartida, o estimador de alavancagem financeira cresceu (em módulo) no montante de $-0,131$. 
Tabela 4 - Resultados das regressões com modelo de estimação da equação de investimento ajustado conforme oportunidades de crescimento (empresas = 247, período de 2001 a 2011)

\begin{tabular}{|c|c|c|c|c|c|c|c|c|c|}
\hline & \multicolumn{3}{|c|}{ Efeitos Fixos (EF) } & \multicolumn{3}{|c|}{ Efeitos Aleatórios (EA) } & \multicolumn{3}{|c|}{ Efeitos Fixos (EF), NW } \\
\hline $\begin{array}{c}\text { Variáveis } \\
\text { Independentes }\end{array}$ & Beta & $\begin{array}{l}\text { Erro- } \\
\text { padrão }\end{array}$ & p-val & Beta & $\begin{array}{l}\text { Erro- } \\
\text { padrão }\end{array}$ & p-val & Beta & $\begin{array}{l}\text { Erro- } \\
\text { padrão }\end{array}$ & p-val \\
\hline $\mathrm{FC}_{\mathrm{i}, t} / \mathrm{I}_{\mathrm{i}, \mathrm{t}-1}$ & 0,214 & 0,067 & 0,001 & 0,257 & 0,065 & 0,000 & 0,214 & 0,090 & 0,018 \\
\hline$Q_{\mathrm{i}, \mathrm{t}-1}$ & 0,080 & 0,046 & 0,082 & 0,065 & 0,043 & 0,134 & 0,080 & 0,042 & 0,057 \\
\hline $\operatorname{ALAV}_{\mathrm{i}, \mathrm{t}-1}$ & $\begin{array}{c}- \\
1,009\end{array}$ & 0,233 & 0,000 & $\begin{array}{c}- \\
1,276\end{array}$ & 0,213 & 0,000 & $\begin{array}{c}- \\
1,009\end{array}$ & 0,266 & 0,000 \\
\hline D X ALAV $\mathrm{A}_{\mathrm{i}, \mathrm{t}-1}$ & 0,153 & 0,104 & 0,140 & 0,165 & 0,101 & 0,101 & 0,153 & 0,107 & 0,153 \\
\hline $\operatorname{VEND}_{\mathrm{i}, \mathrm{t}-1} / \mathrm{I}_{\mathrm{i}, \mathrm{t}-1}$ & 0,407 & 0,024 & 0,000 & 0,401 & 0,021 & 0,000 & 0,407 & 0,036 & 0,000 \\
\hline Dummy tempo & 0,094 & 0,054 & 0,084 & 0,115 & 0,054 & 0,033 & 0,094 & 0,058 & 0,107 \\
\hline Constante & 1,691 & 0,149 & 0,000 & 1,894 & 0,156 & 0,000 & & & \\
\hline $\mathrm{N}^{\circ}$ Observações & \multicolumn{3}{|c|}{1525} & \multicolumn{2}{|c|}{$\mathrm{N}^{\circ}$ Observações } & 1525 & \multicolumn{2}{|c|}{$\mathrm{N}^{\circ}$ Observações } & 1517 \\
\hline Prob $>F$ & \multicolumn{3}{|c|}{0,0000} & \multicolumn{2}{|c|}{ Prob>chi2 } & 0,0000 & \multicolumn{2}{|c|}{ Prob $>F$} & 0,0000 \\
\hline $\mathrm{R}^{2}$ & \multicolumn{3}{|c|}{0,2426} & \multicolumn{2}{|c|}{$\mathrm{R}^{2}$} & 0,2415 & \multicolumn{2}{|c|}{$\mathrm{R}^{2}$} & 0,2426 \\
\hline \multicolumn{10}{|l|}{ Hausman fixed } \\
\hline \multicolumn{10}{|c|}{$\begin{array}{c}\text { Test: Ho: difference in coefficients not } \\
\text { systematic }\end{array}$} \\
\hline \multicolumn{10}{|c|}{ chi2(6) $=(b-B)^{\prime}\left[\left(V_{-} b-V \_B\right)^{\wedge}(-1)\right](b-B)=17,43$} \\
\hline $\begin{array}{c}\text { Prob }>\text { chi } 2= \\
0,0078\end{array}$ & & & & & & & & & \\
\hline
\end{tabular}

Fonte: elaboração própria.

Notas: as variáveis estão expressas por suas respectivas siglas, sendo investimento (INV); fluxo de caixa (FC); $Q$ de Tobin $(Q)$; alavancagem financeira (ALAV); dummy para oportunidades de crescimento multiplicada pela alavancagem financeira (D X ALAV); vendas (VEND) e imobilizado (I). D = é uma variável dummy que é igual a 1 se o $Q$ de Tobin é maior que 1 e igual a 0 em caso contrário. Beta = coeficientes, p-val. = nível de significância dos coeficientes. Prob $>F$, Prob $>$ chi2 $=$ nível de significância do modelo. $\mathrm{R}^{2}=$ coeficiente de explicação do modelo. A alavancagem financeira é obtida pela divisão entre o passivo (dívidas) total e o ativo total. Os resultados foram obtidos pela aplicação do software Stata

Com essa modelagem alternativa houve ainda perda de significância de algumas variáveis.O $Q$ de Tobin, que era sugnificativo ao nível de 5\%, passou a ser significativo apenas ao nível de $10 \%$, já as variáveis dummy de tempo, que eram significativas ao nível de $10 \%$, deixaram de ser significativas a esse nível, que foi o nível mínimo de significância exigida nos testes deste trabalho.

A variável alavancagem financeira revelou-se novamente como a de maior impacto em termos de indicador, sendo agora de $-1,009$. Por outro lado, a nova variável, que inclui uma dummy com valor 1 para empresas com $Q$ de Tobin superior a 1, ou seja, aquelas com altas oportunidades de crescimento, e valor 0 para empresas com esse indicador menor ou igual a 1, consideradas empresas com baixas oportunidades de crescimento, apresentou um coeficiente positivo de 0,153 e estatisticamente não significativo ao nível mínimo exigido (10\%). Esses resultados demonstram que o relacionamento negativo entre 
alavancagem financeira e investimento continua existindo, sendo bastante significativo e mais intenso nas empresas com baixas oportunidades de crescimento, já que elas têm efeito nulo na variável D X ALAV, e o impacto das empresas com altas oportunidades de crescimento passa a ser dividido entre essa variável e a variável ALAV nesse novo modelo. Nessa situação, como já foi afirmado, o estimador se elevou em relação ao modelo base.

Esses resultados são mais uma vez alinhados com os de Aivazian, Ge e Qiu (2005). Apesar da diferença em termos de estimadores, os deste trabalho são superiores aos do anterior; também foi percebida uma elevação (em módulo) no estimador da variável alavancagem financeira, de $-0,335$ para $-0,411$, o coeficiente de D X ALAV também foi positivo $(0,097)$ e os demais estimadores sofreram leve redução no modelo de efeitos fixos em comparação.

Em suma, os resultados permitem concordar com os argumentos de Aivazian, Ge e Qiu (2005) de que a alavancagem financeira tem um impacto negativo estatisticamente significante no investimento, impacto esse ainda mais elevado nas empresas com baixas oportunidades de crescimento. É importante mencionar que essa relação negativa entre a alavancagem financeira $\mathrm{e}$ o investimento torna-se uma constatação relevante para futuros aprofundamentos em termos de análise, por exemplo, das causas desse comportamento. Assim, não pode haver uma interpretação simplista de que as empresas mais alavancadas investiram menos, o que inclusive é descartado, por exemplo, pelo estudo de Kahle e Stulz (2013). Além disso, outros aspectos como a tangibilidade de ativos e a existência de garantias, conforme argumentam Hall (2012) e Norden e Kampen (2013), tornam-se fatores relevantes na relação de investimentos e financiamento por dívidas.

\section{CONSIDERAÇÕES FINAIS}

$\mathrm{O}$ entendimento de que as decisões de investimento são de extrema importância para as empresas, pois elas determinam a possível continuidade das organizações e tornam relevante a tentativa de compreensão de como a alavancagem financeira afeta esse grupo de decisões das entidades. Autores como Myers (1977), Jensen (1986) e Stulz (1990) argumentam que a relação entre as variáveis alavancagem financeira e investimento deveria ser negativa, seja em função da pressão gerada aos fluxos de caixa da empresa pela existência de dívidas (MYERS, 1986) seja pela capacidade que essas tem de mitigar problemas de agência entre acionistas e gestores (JENSEN, 1986; STULZ, 1990). 
Com esse enfoque, trabalhos que relacionam alavancagem financeira $e$ investimento têm sido realizados, entre eles os de Lang, Ofek e Stulz (1996); Aivazian, Ge e Qiu (2005); Firth, Lin e Wong (2008) e Dang (2011). Os resultados e as conclusões, de forma geral, apontam para a relação negativa entre essas duas variáveis. Nessa perspectiva, este trabalho teve como objetivo examinar se a alavancagem financeira afeta as decisões de investimento das empresas brasileiras não financeiras de capital aberto. $\mathrm{O}$ intuito foi utilizar ferramental metodológico aplicado em economias mais desenvolvidas na realidade de um país emergente e apurar o comportamento dos resultados.

Os resultados dos testes desenvolvidos com as empresas desta pesquisa permitem dizer que a alavancagem financeira afeta as decisões de investimento das empresas brasileiras não financeiras de capital aberto, exercendo uma relação negativa, isto é, quanto maior a alavancagem financeira menor é o nível de investimentos das empresas e vice-versa. Entretanto, é importante considerar que a empresa não deixará, ou ao menos não deveria deixar, de investir em função de sua alta alavancagem financeira, o que poderia inclusive afetar sua continuidade. O que se verifica pelos resultados é que as empresas brasileiras não financeiras de capital aberto tendem a investir menos se têm uma alavancagem financeira maior, isto é, quanto mais endividadas menor é o seu nível de investimento. Sendo válido também o contrário, ou seja, quanto menor o seu nível de endividamento maior é o seu volume de investimentos. Um aprofundamento maior no entendimento dessa relação deveria considerar, entre outros fatores, aspectos como tangibilidade de ativos e garantias no processo de obtenção de financiamentos.

É interessante também ressaltar a alta relevância em termos de coeficiente de estimação e significância estatística apurados nos testes, os quais inclusive permitem afirmar que a alavancagem financeira é mais relevante na determinação do investimento no Brasil do que no Canadá, comparando os resultados desta pesquisa com os de Aivazian, Ge e Qiu (2005). Da mesma forma, as variáveis fluxos de caixa e vendas apresentam maior capacidade explicativa do investimento na realidade brasileira. Os testes empregados também possibilitam dizer que a relação negativa entre alavancagem financeira $e$ investimento é ainda mais forte nas empresas com baixas oportunidades de crescimento.

Em linhas gerais, pode-se reconhecer que os resultados encontrados se assemelham aos de estudos anteriores 
que relacionam tais variáveis, como os de Lang, Ofek e Stulz (1996) e, em especial, o de Aivazian, Ge e Qiu (2005). Estudos futuros poderiam focalizar esforços no entendimento dos motivos que levam a esse comportamento das variáveis na realidade brasileira, inclusive verificando se existem motivos para o alinhamento de resultados com as economias desenvolvidas. Ainda como sugestão para pesquisas futuras, indica-se a possibilidade de empregar elementos alternativos para as variáveis utilizadas no modelo, por exemplo, para investimento, fluxo de caixa e outros indicadores de oportunidades de crescimento em substituição ao $Q$ de Tobin e verificar se os resultados continuam semelhantes. Outra sugestão é a aplicação de testes controlados por setor, o que permitiria averiguar se as empresas apresentam diferenças em função dos seus segmentos de atuação.

\section{REFERÊNCIAS}

AHN, S.; DENIS, D. J.; DENIS, D. K. Leverage and investment in diversified firms. Journal of Financial Economics, Amsterdan, v. 79, n. 2, p. 317-337, Feb. 2006.

AIVAZIAN, V. A.; GE, Y.; QIU, J. The impact of leverage on firm investment: canadian evidence. Journal of Corporate Finance, Amsterdan, v. 11, n. 1-2, p. 277291, Mar. 2005.

ASSAF NETO, A. Finanças corporativas e valor. 4. ed. São Paulo: Atlas, 2009. 744 p.
BASTOS, D. D.; NAKAMURA, W.

T. Determinantes da estrutura de capital das companhias abertas no Brasil, México e Chile no período 2001-2006. Revista Contabilidade e Finanças, São Paulo, v. 20, n. 50, p. 75-94, maio-ago. 2009.

BATES, T. W. Asset sales, investment opportunities, and the use of proceeds. The Journal of Finance, Chicago, v. 60, n. 1, p. 105-135, Feb. 2005.

CHILDS, P. D.; MAUER, D. C.; OTT, S. $\mathrm{H}$. Interactions of corporate financing and investment decisions: the effects of agency conflicts. Journal of Financial Economics, Amsterdan, v. 76, n. 3, p. 667-690, June 2005.

CLEARY, S.; POVELL, P.; RAITH, M. The u-shaped investment curve: theory and evidence. Journal of Financial and Quantitative Analysis, Seattle, v. 42, n. 1, p. 1-40, Jan. 2007.

DANG, V. A. Leverage, debt maturity and firm investment: an empirical analysis.

Journal of Business Finance \& Accounting, Hoboken, v. 38, n. 1-2, p. 225-258, Jan.-Mar. 2011.

DEVOS, E. et al. Why are firms unlevered? Journal of Corporate Finance, Amsterdan, v. 18, n. 3, p. 664682, June 2012.

DURAND, D. Cost of debt and equity funds for business: trends and problems in measurement. In: CONFERENCE ON RESEARCH IN BUSINESS FINANCE, 1952, New York. Proceedings... New York: National Bureau of Economic Research, 1952, p. 215-262.

FAMÁ, R.; BARROS, L. A. B. C. $Q$ de Tobin e seu uso em finanças: aspectos metodológicos e conceituais. Caderno de Pesquisas em Administração, São Paulo, v. 7, n. 4, p. 27-43, out.-dez. 2000. 
FAMA, E. F.; FRENCH, K. R. Testing trade-off and pecking order predictions about dividends and debt. The Review of Financial Studies, New York, v. 15, n. 1, p. 1-33, 2002.

FAMÁ, R.; BARROS, L. A. B. C.; SILVEIRA; A. D. M. A estrutura de capital é relevante? Novas evidências a partir de dados norte-americanos e latinoamericanos. Caderno de Pesquisas em Administração, São Paulo, v. 8, n. 2, p. 71-84, abr.-jun. 2001.

FIRTH, M.; LIN, C.; WONG, S. M. L. Leverage and investment under a stateowned bank lending environment: evidence from China. Journal of Corporate Finance, Amsterdan, v. 14, n. 5, p. 642-653, Dec. 2008.

FRANK, M. Z.; GOYAL, V. K. Capital structure decisions: which factors are reliably important? Financial

Management, Tampa, v. 38, n. 1, p. 1-37, spring 2009.

GITMAN, L. J. Princípios de administração financeira. 12. ed. São Paulo: Pearson Prentice Hall, 2010. 775 p.

GUJARATI, D. N.; PORTER, D. C.

Econometria Básica. 5. ed. Porto Alegre: AMGH, 2011. 924 p.

GUNGORAYDINOGLU, A.; ÖZTEKIN, Ö. Firm- and contry-level determinants of corporate leverage: some new international evidence. Journal of Corporate Finance, Amsterdan, v. 17, n. 5, p. 1457-1474, Dec. 2011.

HACKBARTH, D.; MAUER, D. C. Optimal priority structure, capital structure, and investment. The Review of Financial Studies, New York, v. 25, n. 3, p. 747-796, 2012.

HALL, T. W. The collateral channel: evidence on leverage and asset tangibility. Journal of Corporate Finance,
Amsterdan, v. 18, n. 3, p. 570-583, June 2012.

HARRIS, M.; RAVIV, A. The theory of capital structure. The Journal of Finance, Chicago, v. 46, n. 1, p. 297-355, Mar. 1991.

JACKSON, S. B.; KEUNE, T. M.;

SALZSIEDER, L. Debt, equity, and capital investment. Journal of Accounting and Economics, Amsterdan, v. 56, n. 2-3, p. 291-310, 2013.

JENSEN, M. C. Agency costs of free cash flow, corporate finance and takeovers. The American Economic Review, Nashville, v. 76, n. 2, p. 323-329, May 1986.

JONG, A.; VERBEEK, M.;

VERWIJMEREN, P. Firms' debt-equity decisions when the static tradeoff theory and the pecking order theory disagree. Journal of Banking \& Finance, Amsterdan, v. 35, n. 5, p. 1303-1414, May 2011.

KAHLE, K. M.; STULZ, R. M. Access to capital, investment, and financial crisis. Journal of Financial Economics, Amsterdan, v. 110, n. 2, p. 280-299, 2013.

KAYO, E. K.; KIMURA, H. Hierarchical determinants of capital structure. Journal of Banking \& Finance, Amsterdan, v. 35, n. 2, p. 358-371, Feb. 2011.

KIRCH, G.; TERRA, P. R. S.

Determinants of corporate debt maturity in South America: do institutional quality and financial development matter? Journal of Corporate Finance, Amsterdan, v. 18, n. 4, p. 980-993, Sept. 2012.

LANG, L.; OFECK, E.; STULZ, R. M. Leverage, investment, and firm growth. Journal of Financial Economics, Amsterdan, v. 40, n. 1, p. 3-29, 1996. 
MILLER, M. H. Debt and taxes. The Journal of Finance, Chicago, v. 32, n. 2, p. 261-275, May 1977.

MILLER, M. H. Leverage. The Journal of Finance, Chicago, v. 46, n. 2, p. 479-488, June 1991.

MODIGLIANI, F.; MILLER, M. H. The cost of capital, corporation finance and the theory of investment. The American Economic Review, Nashville, v. 48, n. 3, p. 261-297, June 1958.

MODIGLIANI, F.; MILLER, M. H. Corporate income taxes and the cost of capital: a correction. The American Economic Review, Nashville, v. 53, n. 3, p. 433-443, June 1963.

MYERS, S. C. Determinants of Corporate Borrowing. Journal of Financial Economics, Amsterdan, v. 5, n. 2, p. 147 175, Nov. 1977.

MYERS, S. C. The capital structure puzzle. The Journal of Finance, Chicago, v. 39, n. 3, p. 575-592, July 1984.

MYERS, S. C. Capital structure. The Journal of Economic Perspectives, Nashville, v. 15, n. 2, p. 81-102, spring 2001.

NEWEY, W. K.; WEST, K. D. A simple, positive semi-definite, heteroskedasticity and autocorrelation consistent covariance matrix. Econometrica, New York, v. 55, n. 3, p. 703-708, May 1987.

NORDEN, L.; KAMPEN, S. V. Corporate leverage and the collateral channel.

Journal of Banking \& Finance, Amsterdan, v. 37, n. 12, p. 5062-5072, Dec. 2013.

PEROBELLI, F. F. C.; FAMÁ, R. Determinantes da estrutura de capital: aplicação a empresas de capital aberto brasileiras. Revista de Administração da
Universidade de São Paulo, São Paulo, v. 37, n. 3, p. 33-46, jul.-set. 2002.

RICHARDSON, R. J. Pesquisa social: métodos e técnicas. 3. ed. São Paulo Atlas, 1999. $334 \mathrm{p}$.

ROSS, S. A.; WESTERFIELD, R. W.; JORDAN, B. D. Administração financeira. São Paulo: McGraw Hill, 2008. $795 \mathrm{p}$.

SHIN, H.; STULZ, R. M. Firm value, risk and growth opportunities. NBER Working Paper Series, Cambridge, Working Paper 7808, July 2000. Disponível em: <http://www.nber.org/papers/w7808>. Acesso em: 24 jan. 2013.

STEVENSON, W. J. Estatística aplicada à administração. São Paulo: Harbra, 2001.496 p.

STULZ, R. M. Managerial discretion and optimal financing policies. Journal of Financial Economics, Amsterdan, v. 26, n. 1, p. 3-27, July 1990.

TRIOLA, M. F. Introdução à Estatística. 9. ed. Rio de Janeiro: LTC, 2005. 726 p.

VALLE, M. R. Estrutura de capital de empresas brasileiras num ambiente de altas taxas de juros e na presença de fontes diferenciadas de financiamento. 2008. 104 f. Tese (Livre Docência) Departamento de Contabilidade, Faculdade de Economia, Administração e Contabilidade de Ribeirão Preto, Universidade de São Paulo, Ribeirão Preto, 2008.

WHITED, T. M. Debt, liquidity constraints, and corporate investment: evidence from panel data. The Journal of Finance, Chicago, v. 47, n. 4, p. 1425-1460, Sept. 1992. 
YANG, B. Dynamic capital structure with heterogeneous beliefs and market timing. Journal of Corporate Finance, Amsterdan, v. 22, p. 254-277, Sept. 2013. 